\title{
Los vericuetos temporales del mito
}

\author{
ENRIQUE LUQUE \\ Universidad Autónoma de Madrid
}

\section{RESUMEN}

Si el mito religioso se asocia con lo sagrado y la negación del tiempo, el fenómeno profético es, en principio, ambivalente: pertenece tanto al ámbito de lo sagrado como a lo profano. Pero su imbricación con la atemporalidad, como pone de manifiesto el análisis del judaísmo, termina por situar lo profético en el dominio de lo eterno o repetitivo, por oposición al tiempo singular y lineal que el mito religioso combate. Ahora bien, existe el mito profano aparte del religioso, como cabe distinguir a la profecía profana de la sagrada. Esta distinción puede ser más fructífera que la que separa a la historia del mito. El mito profano, como el religioso (como cualquier lenguaje), utiliza signos, sólo que de distinto significado; pero además, por contraposición al religioso, el mito profano está como impregnado de tiempo: aparece y desaparece vertiginosamente.

Palabras clave: Tiempo mítico, Tiempo singular y lineal, Profecía, Judaísmo, Historia, Mito profano, Max Weber, Claude Lévi-Strauss, Roland Barthes.

\section{SUMMARY}

If the religious myth is associated with the sacred and the denial of time, prophecy is, at first glance, ambivalent: it belongs to both the realm of the sacred and that of the profane. However, because of its intertwining with timelessness, as the analysis of Judaism shows, prophecy ends up better defined in connection with the eternal or repetitive, as opposed to the unique, linear time that religious myths antagonize. Nonetheless, one should distinguish between religious myths and profane myths, as one should differentiate between sacred prophecies and profane ones. Such a distinction can be more fruitful than the difference between myth and history. The profane myth, like the religious one (like any language), uses signs, yet with other meanings. Furthermore, unlike the religious myth, the profane myth is sort of impregnated with time: it comes and goes rather quickly.

Key words: Mythical Time, Unique and Linear Time, Prophecy, Judaism, History, Profane Myth, Max Weber, Claude Lévi-Strauss, Roland Barthes.

RDTP, LIX, 1 (2004): 17-36 
Los mitos, dijo hace años Lévi-Strauss, son máquinas para destruir el tiempo: una bella metáfora que, como todas, ilumina por lo menos tanto como ensombrece conceptos y realidades. Volveré enseguida a esta y otras metáforas; pero antes, unas palabras sobre el tiempo y su inevitable correlato: el espacio. Tiempo y espacio son, como es sabido, conceptos fundamentales de cualquier cosmovisión física. Pero de forma muy diferente o casi contrapuesta: aislados en el universo newtoniano, estrechamente relacionados en el universo que presupone la teoría de la relatividad einsteiniana. En el primer caso, el espacio euclidiano, tridimensional, se concibe como ilimitado y atemporal. En el segundo, en cambio, a las tres dimensiones convencionales viene a añadirse el tiempo como una cuarta. De ese modo, el espacio-tiempo se convierte en una única estructura cuatri dimensional que engloba ambos conceptos.

Ahora bien, la física, antes o después de Einstein, poco o nada afecta al modo como percibimos el mundo en el que vivimos. A medio camino entre las reflexiones abstractas y las percepciones de cada día, Spengler escribió unas interesantes páginas sobre los contrastes entre tiempo y espacio. Obsesionado por su tiempo, el autor alemán vio en el espacio algo inerte, sin vida y puramente pensado; el tiempo, en cambio, tenía algo de incomprensible y de fundamentalmente vital. Como otros muchos que se han aventurado en los vericuetos de la comprensión del tiempo, Spengler evocaba también la famosa frase de san Agustín: Si nemo ex me quaerat, scio; si quaerenti explicare velim, nescio, para señalar que el espacio, muerto, es un concepto, mientras que el tiempo, orgánico y vivo, es inconcebible. En síntesis: "El tiempo es un contraconcepto del espacio" (Spengler 1998: 246). Retengamos esta idea del tiempo como algo vivo y fundamentalmente humano: somos el tiempo (ibid: 239).

Volvamos ahora a las metáforas, si es que las habíamos abandonado. Cualquier lenguaje hace uso de muchas otras menos conscientes que la que mencionaba al principio; pero no menos dotadas de luces y de sombras. Son las metáforas de la vida cotidiana o, en la expresión de Lakoff y Johnson (1980), metáforas con las que convivimos (metaphors we live by). Apenas si las percibimos, pero regulan tanto nuestra peculiar instalación en el mundo como los cambios de nuestros mundos, según estos autores. Piénsese, por ejemplo, en esa metáfora, occidental y capitalista, que equipara al tiempo con una mercancía: el tiempo es dinero o el tiempo es oro. Vertida hace mucho a muchos idiomas, la metáfora ha precedido a eso que hoy conocemos como globalización o a la universalización del concepto de mercado. Pues bien: hay otras metáforas, menos literarias e inconscientes aún, mucho más imperceptibles, que ponen de manifiesto cómo nuestra concepción del tiempo está estrechamente asociada a nuestra posición en el espacio. Éste es, en 
muchos idiomas, el cauce metafórico del tiempo. En el espacio se está, mientras que el tiempo nos espera en algún sitio (nos acercamos a fin de año...), se desplaza hacia donde nos encontramos (cuando llegue el verano...), o transita a nuestro lado (cuando pasen dos semanas...) ${ }^{1}$.

Por otra parte, los contextos sociales imprimen un sello singular a ese nexo de tiempo y espacio. Así, en una sociedad tradicional, marcada por los ritmos estacionales, una y otra entidad se conciben como un todo e intercambian sus ropajes. Del encadenamiento de las faenas agrícolas en una comunidad rural próxima a Granada escribí hace ya muchos años: "Es éste un sistema de tiempo en el que se conceptualizan los desplazamientos espaciales como en una serie cronológica. E, incluso, el espacio mismo: antes, para indicar que la tierra presentaba condiciones óptimas para la siembra, que estaba llegando el tiempo de la siembra, se decía que el campo tenía buen tempero" (Luque 1974: 25). De una sociedad tribal, la de los tiv de Nigeria, se nos muestra cómo fue ampliando su concepción del espacio —originariamente confinada al territorio de la tribu - por el sencillo expediente de agregar antepasados (esto es, tiempo) al fundador mítico, hasta asimilar a Adán y Eva e incorporar de ese modo a los europeos como otro linaje más (Bohannan 1967).

De una u otra forma, el transcurrir temporal parece requerir siempre cauces. Además, lo inerte y estable domina claramente sobre lo vivo y movedizo. Tal vez por eso el mito prefiere lo primero y trata de excluir - $\mathrm{O}$ destruir - lo segundo. Cuando Lévi-Strauss se refiere al mito y al tiempo en esos términos, lo hace evocando la ilusión de permanencia que el mito sugiere; porque el antropólogo francés equipara el mito con la música en tanto que uno y otra rompen, al menos momentáneamente, la fugacidad de nuestras existencias e instauran la ilusión de lo repetitivo y de lo eterno. Como dice Benveniste (1966), las palabras con las que el Génesis describe la creación del mundo producen el efecto de que, repetidas generación tras generación, el mundo comience cuando alguien las pronuncia. Palabra y mito son, realmente, inseparables del surgir humano, como resaltara Giambattista Vico hace ya cerca de trescientos años y concluye hoy un ambicioso estudio del simbolismo ritual: la religión es tan antigua como el lenguaje, o lo que es lo mismo, tan antigua como la bumanidad (Rappaport 2001: 46) (énfasis mío). Pero hay transgresiones y transgresores frente a lo repetitivo y lo permanente y, curiosamente, tienen mucho que ver con la palabra y con el ámbito del mito y de la religión. Se trata de la profecía y de los profetas, a cuyo papel quiero dedicar buena parte de las páginas que siguen.

${ }^{1}$ Para todo lo anterior, Cf. Lakoff y Johnson (1980: 41ss., 126, 145). Una buena exposición crítica de esta y otras teorías acerca de la metáfora en Bustos (2000). 


\section{MITO Y PROFECÍA}

Hay en el análisis de la religión y del ritual una importante tendencia cuyos hitos más importantes pueden concretarse en los nombres de Durkheim, Van Gennep, Wallace y Victor Turner. En esta misma línea se inserta esa póstuma contribución de Rappaport a la que acabo de aludir. En este sentido, lo sagrado se sitúa frente a lo profano como categoría antitética. Rappaport acentúa aún más el contraste: el ritual implica el abandono de los tempos que caracterizan a nuestra vida cotidiana. La liturgia reemplaza esos tempos por una unión extraordinaria de lo rápido y lo inmutable: una unión que trata de reproducir, en el tempo ritual, la eternidad e incluso la inmortalidad. De ese modo, el tempo litúrgico se convierte en un tiempo fuera del tiempo.

Rappaport busca, más allá de contextos específicamente socioculturales, ese radical antagonismo entre lo sagrado y lo profano. Es - dice, siguiendo a algunos neurobiólogos - nuestra propia estructura cerebral la que se ve envuelta en el contraste. Así - argumenta-, es el hemisferio cerebral no dominante, el derecho, el que parece convertirse en protagonista durante el desarrollo del ritual. Los mecanismos habituales del ritual (ritmo, repetición, ingestión de drogas, dolor, éxtasis...) corresponden o afectan a ese hemisferio, frente a aquellos otros que regula el hemisferio izquierdo (discurso, razonamiento analítico, sentido de la duración...). El tiempo cotidiano -0 el tiempo, sin más - queda, así, suspendido o paralizado mientras impera el tiempo fuera del tiempo o —en la frase de Lévi-Strauss - aquel que, como mito, se encarga de matar nuestros tiempos humanos. Éstos, a diferencia del tempo litúrgico o sagrado, son irrepetibles. O, más exactamente, como apunta Rappaport, difícil o estadísticamente irrepetibles. Recordemos, si no, la famosa frase de Marx en el Dieciocho de Brumario de Luis Bonaparte: la historia no se repite como tragedia, sino como farsa. El suceso mítico —creación del mundo o del hombre, invención del fuego o de la palabra- es, por el contrario -dice Rappaport-, mecánica o estructuralmente singular e irreversible, pero repetible en el recitado litúrgico. Y concluye: "Si la esencia de la historia es el paso de lo particular, la esencia del orden litúrgico es la repetición de lo inmutable" (2001: 333).

Justamente, lo que choca del fenómeno profético es su pertenencia a estos dos ámbitos (sagrado/profano, eternidad/historia) tan radicalmente diferenciados por esa línea de análisis sociológico de la religión. El iniciador de la misma, Durkheim, centró su investigación señera en lo que, en su época, se consideraba la religión y la gente más primitivas del mundo: las de Australia. Sencillamente porque, pensaba, "la imaginación popular o sacerdotal no ha tenido allí ni tiempo ni medios de transformar la materia prima de las 
ideas y de las prácticas religiosas" (Durkheim 1960: 8). Desde esta perspectiva, por tanto, el análisis del hecho religioso sólo puede comenzar allí donde la historia parece no haber intervenido. Max Weber, por el contrario, situó el fenómeno religioso, en general, en un contexto conflictivo y, por ende, histórico. Desde su enfoque, las prácticas religiosas no son sino reliquias de antiguas luchas entre bombres sufrientes, combativos y de acción (Weber en Bendix 1969: 266) (énfasis mío). Nada tiene de extraño que dedicara sus mayores esfuerzos intelectuales en este campo al estudio del judaísmo antiguo y a resaltar los contrastes entre la religión de Israel y las de las grandes civilizaciones de la Antigüedad (Weber 1952).

Pero, ¿de qué hablamos cuando utilizamos los términos profeta y profetismo? De entrada, la postura durkheimiana, recelosa frente a ambos, no es única ni original. Como ya apuntara Dorothy Emmet (1956), Durkheim abordó este tema casi de refilón: no tanto por lo que respecta a la religión como por lo que se refiere a la desviación social y en estrecha relación con el rol desempeñado por los delincuentes. En ese recelo ante el profetismo tiene tras de sí el sociólogo francés un ilustre y escéptico compatriota, Michel de Montaigne (1992), quien había escrito páginas muy severas contra una de las aficiones de su época: la de hacer pronósticos. Montaigne recurrió a Cicerón para recordar que no es útil conocer el porvenir, porque es deplorable angustiarse sin provecho. También su coetáneo inglés, Francis Bacon, otro gran ensayista, dejó clara su postura con respecto a lo que denominó, sin más, profecias: "Mi juicio es que deben ser ignoradas y no deberían servir más que para charlas invernales junto a la chimenea" (2000: 132); pero aclaraba inmediatamente: ignoradas por lo que se refiere a darles crédito, ya que su difusión debe ser perseguida legalmente. Claro que Bacon se curaba en salud y dejaba fuera de su menosprecio las que denominaba "profecías divinas" (esto es, las relativas al Mesías y al Pueblo Elegido).

Esa cautela baconiana puede ser pertinente en el terreno de la ortodoxia, pero de escasa utilidad cuando se quiere entender el fenómeno del profetismo desde una perspectiva sociocultural. Como ha resaltado Neher (1972), la experiencia profética abarca muchas posibilidades, que van desde la pura magia a la más excelsa mística. Pero entre todos los posibles puntos de ese continuum hay una profunda afinidad. Igualmente, Neher recalca cómo el profeta se sitúa tanto en el plano trascendente, religioso, como en el tiempo de la historia. Fue, sin duda, esa característica de la profecía bíblica la que atrajo hacia ella el interés weberiano. Porque, a diferencia de las divinidades hindúes, que consagran un orden inmutable, Yahvé opta por vincularse: su poder estriba, justamente, en que sus imperativos pueden cambiarse mediante nuevas revelaciones y nuevas alianzas.

Quiero destacar en lo que sigue tres puntos de encuentro, dentro del 
marco bíblico, entre lo atemporal, eterno o repetitivo, de un lado, y lo singular, irrepetible o temporal, de otro. En primer lugar, el entrecruzamiento de hechos históricos - por fantaseados que el relato canónico nos los haya hecho conocer-y de elementos claramente míticos. En segundo lugar, la forma y el contenido del mensaje profético. Por último, la imbricación del tiempo histórico, lineal, con lo que los antropólogos denominan el tiempo ecológico (esto es, circular o cíclico), formulado magistralmente -como es sabido- por Evans-Pritchard (1940). A mi juicio, el resultado de esta triple concurrencia y confrontación entre el tiempo y sus antagonistas (lo eterno, la repetición; el no tiempo, en suma) tiene como claro perdedor, a la larga, al primero. Dicho de otro modo: hasta la misma singularidad profética a la que apuntaba Weber termina por diluirse en sus extremos atemporales, como mostraré después.

\section{ENTRECRUZAMIENTO DE HISTORIA Y MITO}

Pero vayamos por partes. Para empezar, hay que tener en cuenta que la dualidad de nombres del dios de Israel responde, precisamente, al enorme peso del factor temporal: "El" $\multimap$ "Elohim", en realidad un plural, pero usado como singular-y "Yahvé". El primero es, ante todo, el dios de los patriarcas. Yahvé entra en escena mucho más tarde: a partir de la experiencia histórica de la liberación de Egipto y el Éxodo. A diferencia de las religiones de su entorno cultural y geográfico, la del pueblo de Israel descarta los procedimientos habituales de relacionarse con lo sagrado, nos dice Von Rad (1972); esto es, la pluralidad de nombres de sus dioses (los cincuenta de Marduk, los muchos nombres de Ra) o la ocultación de sus nombres (el verdadero nombre de Amón, la ignorancia ritual de los nombres divinos en Babilonia). Yahvé, por el contrario, se autorevela históricamente a todo su pueblo y no sólo a iniciados. La singularidad de este pueblo y de esta religión radica en evitar que el nombre divino entre en la esfera del misterio: "Israel no podía apoderarse del nombre de Yahvé y hacerlo objeto de una mitología o especulación profunda; sólo podía comprenderlo en el ámbito de la experiencia histórica" (Von Rad 1972: I, 241-242).

Ha sido Rainer Albertz quien, más recientemente (1999), ha hecho especial hincapié en la peculiaridad de esa experiencia. Yahvé no era, primitivamente, sino un dios de la tormenta de origen madianita; fue Moisés quien conectó esta fuerza de la naturaleza divinizada con la liberación de Egipto: un hecho probablemente fantaseado, pero acaecido de alguna manera. Dicho de otro modo: la revelación del Sinaí opera como un nexo entre la repetición - la del mito y la del meteoro- y lo irrepetible, el acontecimiento. El grupo 
del Éxodo - y vuelvo a Albertz-, el grupo salvado por la intervención de Yahvé, será quien funde la religión de Israel, mancomunadamente con las poblaciones asentadas en Canaán. De ese modo, Yahvé no aparece tanto como el dios de un orden eterno cuanto el de una asociación política (Weber) y, por tanto, contingente. La mancomunidad, a su vez, es fruto del sincretismo de $\mathrm{El}$ y Yahvé. $\mathrm{El}$ - en semítico noroccidental- es tanto nombre genérico de dios como nombre de una divinidad concreta. Como lo segundo, forma parte del nombre de la confederación, que constituye, a su vez, una comunidad de culto (Weber): Yisra' el (esto es, "Dios —o El— reina", o quizá "Que Dios —o El— se muestre como soberano"; Albertz cree más probable esta denominación específica; Weber había resaltado, en cambio, la genérica: "El pueblo del dios batallador"). En todo caso, lo fundamental es que la confederación tribal, acéfala y segmentada, adopta un carácter decididamente igualitario y antimonárquico. Elohim era un dios semítico, preeminente, pero vinculado al panteón cananeo; Yahvé, en cambio, ajeno al panteón local aunque fusionado con El, se configura como el garante de la unidad tribal y de su independencia. A Yahvé se le atribuye la propiedad de la tierra: una noción derivada probablemente del primitivo dios El y muy común en el Oriente antiguo. Es más, acaba por recordar a los israelitas que también la tierra le pertenece: "El campo es mío, vosotros sois sólo advenedizos y colonos en mi casa" (Levítico 25, 23) (Von Rad 1972: I, 51). Pero Yahvé es, sobre todo, el dios que salvaguarda el espíritu antijerárquico y antimonárquico en el que se basa la confederación. Así, Gedeón, tras "su victoria contra los madianitas, rehúsa la oferta de convertirse en 'jefe' del pueblo con las palabras ' $\mathrm{Ni}$ yo ni mi hijo seremos vuestro jefe. Vuestro único jefe es Yahvé (Jueces 8, 22 ss.)" (Albertz 1999: 148). También asume Yahvé otra cualidad eloísta, la de creador del mundo, e, igualmente, otros atributos, babilónicos y de áreas próximas. De ese modo, concluye Albertz, "Yahvé entró en relación con todos los niveles de la realidad. Yahvé no era ya solamente el Dios de la historia, sino también el Dios de la naturaleza. Su acción rebasaba las fronteras de Israel. La pervivencia de la propia sociedad, más aún, la estabilidad del universo, dependía de su poderosa y providente actuación" (ibid.: 249). Como apunta este autor, el precio de esta especie de universalización de Yahvé — - rey ya de dioses y de pueblos - fue su transformación de dios de oprimidos en dios de opresores. "'Yahvé, rey del cielo', suplantó la tradición más antigua del Yahvé que viene del Sinaí" (Von Rad 1972: I, 49).

La profecía propiamente dicha entra en juego tardíamente, en época monárquica. Los profetas, en el sentido del amplio espectro semántico al que se refiere Neher (1972), de la mántica a la mística, eran frecuentes en las cortes orientales: sus servicios había que pagarlos y ello requería eștándares económicos bastante más sofisticados que los que caracterizan a una simple 
confederación tribal. Pero la profecía bíblica presenta rasgos poco frecuentes en el área. El profeta del judaísmo antiguo -como resaltó Weber- acostumbra a pronosticar desgracias más que a dar buenos augurios, y eso no suele pagarse. Weber contrasta de modo agudo al profeta y al sacerdote, en tanto que dos tipos dispares de liderazgo: carismático y tradicional. Hay razones —señaló ya Peter L. Berger (1963) — para pensar que el sociólogo alemán extremaba la antítesis; y ello debido tal vez, en parte, a la exigencia metodológica de sus tipos ideales y, en parte, al estado de los conocimientos bíblicos de su época: con posterioridad, a partir de los años veinte del pasado siglo, algunos de los exponentes de la denominada Escuela de Upsala exageraron incluso la equiparación de sacerdotes y profetas ${ }^{2}$.

Ahora bien, probablemente, Weber no estuvo desacertado al subrayar el papel contracultural de la profecía bíblica o de algunas de sus manifestaciones; si bien no en el sentido de una fuerza social que empuja hacia adelante, sino más bien en el de una reacción utópica (vuelta a un sencillo pasado campesino o incluso nómada) frente a la burocracia real y sus fastos orientales. En parecida línea argumental, Albertz nos muestra cómo los dos frentes de ataque de la profecía se dirigen tanto a la denuncia de injusticias sociales como a la oposición neta a las alianzas políticas y militares de Israel. En el primer caso, los embates se lanzan contra la acumulación de tierras en manos de latifundistas, los préstamos usurarios y la esclavitud derivada de su imposible pago, el lujo de palacios y fiestas, la corrupción de los jueces venales, que convierte la administración de justicia en instrumento de los poderosos, etc. Los profetas, dice Albertz (1999: 311), "no convocan a los campesinos a una revolución social [...], no hacen sino preparar el camino para que vuelva a resurgir aquel impulso de liberación iniciado en su día por las pretensiones de la religión yahvista". En cuanto a las alianzas, constituían - para Isaías concretamente, abanderado de este tipo de profecías- alejamiento de Yahvé; por eso ataca tanto la sumisión de Acaz al poder asirio como la alianza de Ezequías con Egipto: ambas manifestaban falta de confianza en Yahvé.

\section{EL TIEMPO EN EL MENSAJE PROFÉTICO}

Pero vayamos más directamente al tiempo como locus privilegiado de la profecía. Con ello pasamos al segundo punto de convergencia entre aquél y el mito. Neher (1972: 208) llega a extremar la inversión de valores que la

\footnotetext{
${ }^{2}$ Véase también Neher (1972: 254 ss.). En otro sentido, se ha señalado igualmente cómo Weber subestimó la dimensión nacional y política de la teodicea profética (véase Raphel 1970).
} 
profecía conlleva: "Todo lo que es exterior, extenso, espacial, es contingente. Sólo el tiempo es absoluto. Puede ser que Dios esté lejos en el espacio. Pero sigue estando muy cerca por el tiempo. El Estado y el Templo pueden derrumbarse, pero la alianza subsiste gracias a la existencia de cada hebreo". No deja de ser interesante subrayar que el tema oriental de la lucha originaria contra el caos se despoja bíblicamente de su carácter mitológico y se transmuta en historia política como triunfo de Yahvé sobre los enemigos de Israel (Albertz). Por otra parte, el propio cometido profético está limitado: en el tiempo, a una misión concreta (Von Rad). No se trata, como recalca Weber, de que otras religiones desconozcan la intervención de los dioses en la buena o la mala fortuna de los hombres: lo que hace peculiar al profetismo judío en el contexto de las religiones de la época y de la zona es que la intervención divina se configura como algo que se va a producir en un futuro inmediato. En ausencia de un orden establecido para siempre, la ventura o la desgracia tienen que acaecer en el breve transcurso vital de justos y pecadores. Precisamente, la muerte de la profecía se produce, como mostraré después, cuando ésta se remite a los orígenes o a las postrimerías: en definitiva, fuera del tiempo.

El tiempo en la profecía se manifiesta también de otra guisa: se trata de los modos que el mensaje profético va adquiriendo en el transcurso de la historia de Israel. Von Rad se refiere al mensaje expresado en palabras - la palabra de Dios, asi habla Yabvé- como una forma tardía y elaborada que contrasta con la forma primitiva: el grito profético, utilizado fundamentalmente en el combate. La fórmula elaborada, pienso, engloba la antigua, ya que se inicia con una invectiva o una exhortación del profeta o mensajero, destinada a llamar la atención, seguida por el mensaje o palabra divinos. Neher, por su parte, expone también dos figuras del mensaje profético como "constantemente contemporáneas", pero enseguida percibimos una secuencia temporal como la que acabo de apuntar: se trata de la ruab (pneuma, espíritu) y el dabar (logos, palabra). La ruab es, continúa este autor, múltiple e incluso contradictoria. Es, por supuesto, espíritu de Dios, pero también principio vital: algo tan material como el aire y el viento, sede de impulsos y sentimientos (divinos y humanos), individual y colectiva, pura e impura... Noción, como se ve, física, moral, religiosa..., pero no atemporal. Con ella también volvemos a toparnos con el tiempo y con la historia: "La ruab de Dios se juzga a sí misma: se arrepiente. Ese arrepentimiento de Dios bastaría para demostrar que el Dios bíblico no está ligado a un principio abstracto y general. No es el Dios de los principios universales, sino el Dios de lo Único, del momento histórico" (Neher 1972: 86).

El dabar es paralelo a la ruab, pero muy diferente del espíritu. En este caso, no se da la ambigüedad sino una gran concreción, la palabra: "Es sig- 
nificativo que siempre aparece, con enérgica determinación, como 'la palabra de Yahvé' y no con la forma indeterminada de 'una palabra de Yahvé', lo que dado el gran número de 'acontecimientos de la palabra' pudiera parecer lo más propio" (Von Rad 1972: 118). La ruab es oscura, enigmática y subjetiva y tiene que ser descifrada; en cambio, el dabar es objetivo y no da lugar a la subjetividad de las visiones proféticas: "La palabra es la madurez del espíritu [...]. Todo el terreno de la ruab sigue siendo subjetivo. Se trata de la relación de la primera persona; el yo del profeta queda sometido a una experiencia que él es capaz de describir, de comprender, de conocer, pero que no puede situar delante de él para juzgarla. Es lo que pasa con los sueños, con las visiones, con los éxtasis [...]. Pero el terreno del dabar es objetivo: en lugar del yo del profeta aparece un él: palabra de Dios, discurso de Dios... Las palabras no exigen ya ni un relato ni una interpretación. Sencillamente son [...]. La ruab de Dios y la ruab del hombre corren el peligro de no constituir más que una sola cosa. Pero cuando Dios habla, Dios y el hombre son distintos. El dabar es diálogo [...]; en relación con el dabar, con el logos, la ruab no es más que un prólogo" (Neher 1972: 98). La ruab, sigue Neher, es magia y silencio: lo opuesto a la palabra y a la revelación. Desde el inicio, además, el contraste entre el no-tiempo y el principio de los tiempos es patente: "en la descripción del Génesis, la ruab no puede hacer otra cosa que cernerse sobre el caos, mientras que la palabra lo organiza. Y dijo Dios: Hágase la luz (Gén 1, 2-3). La palabra de Dios es creadora" (ibid:: 101). Más aun, la palabra se equipara con la historia: "Dibré Selomó, las palabras de Salomón son sus acciones, su historia [...]. La ruab introducía en el mundo a un Dios vivo, pero que no lo modificaba. La palabra de Dios hacía al universo histórico" (ibid:: 101-102) ${ }^{3}$.

¿Se sitúa, entonces, el dabar en el ámbito de lo que consideramos historia y de ese tiempo que el mito destruye? Las cosas son bastante más complicadas. Ante todo, y pese a los contrastes apuntados, hay una gran afinidad entre ruab y dabar. El conocimiento, la relación profética con la divinidad, sea mediante el espíritu o la palabra, se expresa igualmente con alegorías

\footnotetext{
${ }^{3}$ Tal vez habría que resaltar aquí que la palabra y su significado son, especialmente en el ámbito de lo religioso, los análogos de tiempo y eternidad, en el sentido que plantea estos temas Kenneth Burke al referirse a las Confesiones de San Agustín: "el significado de la frase es una esencia, una especie de significación o definición fijada que no se confina a ninguna de sus partes, sino que permea o inspira la frase como un todo. Tal significado, yo diría, es análogo a 'eternidad'. En contraste con el flujo de la frase, donde cada sílaba surge, existe durante un momento y luego 'muere' para dejar lugar al próximo estadio del proceso continuo, el significado es 'no-temporal', aunque corporizado (encarnado) en una serie temporal. El significado, en su unidad o simplicidad, 'es, sin más'” (Burke 1970: 27).
} 
cinegéticas y amorosas: el león y su presa, el ave y la trampa, el hombre y la mujer. Escribe Jeremías: "Me has seducido Yahvé, y yo me dejé seducir"; Amós: "El león ha rugido, ¿quién no temerá? El Señor Yahvé ha hablado, ¿quién no profetizará?" (Von Rad 1972: II, 81). "Jeremías experimenta patéticamente el conocimiento profético como una seducción, como una violación. Pocos profetas ha habido que hayan tenido en el mismo grado que Jeremías la sensación aguda y torturante de estar poseídos por Dios. Es verdad que en este caso la posesión viene del dabar de Dios, y no de su ruab; pero es en ambos casos una posesión irracional, eruptiva" (Neher 1972: 95). Yahvé es celoso y vengativo: "Dos cosas le decía este celo a Israel: el afecto de Yahvé -Oseas habla de él como de la pasión del enamorado-; pero también la amenaza del castigo si se entregaba al Señor con el corazón a medias" (Von Rad 1972: I, 267).

Por otra parte, al poder creativo de la palabra no son ajenos ni mucho menos otros mundos religiosos ni otras áreas culturales. En este sentido, Tambiah (1985) ha visto reflejados en la Biblia un conjunto de postulados que cree descubrir tanto en las religiones antiguas como en las culturas conocidas en nuestros días gracias a la observación etnográfica. Así, los himnos védicos se refieren a vàc, 'la palabra', y se afirma allí que los dioses gobiernan el mundo con fórmulas mágicas; en la religión persa, tras la batalla del bien y el mal, es la palabra la que hace que el caos se transforme en cosmos; los egipcios conocieron un Dios de la Palabra y, más cercanos al mundo bíblico, semitas y sumerios creían que el mundo había sido creado por la palabra (véase asimismo Von Rad 1972: I, 192 ss.). Tambiah señala igualmente que nociones similares aparecen en el budismo y también las reflejan pueblos melanesios como los dobuanos o los trobriandeses. Sin duda, la tradición bíblica — judía primero y luego sus secuelas cristiana e islámica- ha extremado el carácter de creación ex nibilo por la palabra frente a otras religiones y otros sistemas filosóficos. Como ha puesto de relieve Scholem (1998: 47 ss.), el contraste es patente con la filosofía griega y, concretamente, con la aristotélica: como se dice en la Metafísica, nibil ex nibilo fit, nada se hace de la nada ${ }^{4}$. Pero no hay que trazar fosos insalvables entre lo mágico y lo religioso, entre esto y lo puramente racional o entre el conjuro y la revelación.

${ }^{4}$ Scholem, por otra parte, añade: "El discurso de una creación de la nada es tardío" (ibid.: 49). Sobre el juego de palabras místico que asocia el 'Yo' de Dios con la 'nada' (ani y ain) en la mística medieval judía, véase también Scholem (2000: 241ss.). En su sentido primigenio, en cambio, no hay que ver un significado metafísico en el concepto de crear ni, por tanto, entenderlo como tránsito del no-ser al ser, ya que los términos semíticos que traduce la palabra "crear" hacen referencia a simples actividades artesanales: curtido de pieles, moldeado de arcilla o trabajos de albañilería (Gaster 1973: 9, 287). 
Es el propio Von Rad quien evoca esa mentalidad, mágica y primitiva, al referirse a la unidad de la palabra con la cosa: a través del nombre, Adán confirma la existencia de los animales y se apropia de ellos. "Dabar es una cosa concreta, actual y activamente vital" (Th. C. Vriezen en Von Rad 1972: II, 111). La palabra tiene, evidentemente, algo cósico - sigue Von Rad- que actúa como una especie de proyectil: "El Señor ha lanzado una palabra contra Jacob y ella ha caído sobre Israel", escribe Isaías (ibid:: II, 121). Ahora bien, paradójicamente, esa palabra-objeto tiene efectos históricos, de especificidad cultural. Es la palabra de Yabvé la que diferencia al profeta de otros magos, como es también el rugir de Yahvé el que aparta al profeta de "cualquier convencionalismo cúltico o religioso" (ibid.: II, 120-122). También Neher (1972: 94) resalta la singularidad de la evolución profética frente al espiritu, que equipara nebiim (profetas) y mechugaim (locos) "los profetas mayores, a partir del siglo VIII [antes de nuestra era] [...] no se definen como captados por el espíritu, sino como alcanzados por la palabra de Dios. Lejos de ser poseídos, son ellos los posesores de la palabra divina. Desconfían de los profetas poseídos, pneumáticos, y consideran incluso su inspiración por la ruah como un criterio de impostura. Solamente en la época del Destierro volverá a reaparecer la muab en la profecía bíblica". Y, entonces y a partir de entonces, por influencias foráneas (sirias y caldeas), según el mismo autor.

\section{TIEMPO HISTÓRICO Y TIEMPO ECOLÓGICO}

Ahora bien, hablar de tiempo y de historia implica sugerir diversidad y peculiaridades. Con ello entramos en el último de los entrecruzamientos del tiempo y sus contrapartidas. Hay que tener en cuenta que Israel, como otras muchas sociedades tradicionales, no concibió el tiempo en sentido abstracto ni lineal. Así argumenta Von Rad, quien añade que el tiempo que refleja la Biblia es un tiempo lleno; lleno de sucesos, de hechos concretos, se entiende: "no se puede pensar un suceso sin su tiempo, ni un tiempo sin su suceso" (1972: II, 133). Como en el caso de la comunidad rural a que aludía al principio, más que de un tiempo se trata de tiempos (para nacer, para construir un nuevo templo, recoger el rebaño o guerrear). Además, la sucesión de esos tiempos es rítmica; no azarosa, sino previsible y ordenada. Son las fiestas las que regulan ese tiempo cíclico. No obstante, lo característico de Israel fue que bistoriara - como subraya este mismo autor- fiestas puramente agrícolas y, por ende, cíclicas. Así, por ejemplo, la recolección de la cebada conmemoraba la salida de Egipto, del mismo modo que la vendimia evocaba el tiempo del desierto y de las tiendas. Más aun, lo que eran en realidad elementos independientes quedaron engarzados en una continui- 
dad histórica: tiempo de los patriarcas, Éxodo, inmigración en las tierras de Canaán. Los planos mítico e histórico se entrecruzan: "la contingente experiencia histórica del poder de Dios se exalta a categoría mítica y se actualiza regularmente en el culto [...]; no sólo se produce una 'historificación del mito', sino también una 'mitificación de la historia"' (Albertz 1999: 247). Albertz se refiere, concretamente, a la tan poco resaltada coexistencia (en bistorias sagradas convencionales) del Yahvé mosaico y el Baal cananeo. Tal coexistencia, destaca este autor, no tenía nada que ver con el sincretismo - ya apuntado- de El y Yahvé; entre otras cosas, porque en este caso no se trató de una fusión sino de una tensión permanente entre el dios del Sinaí y el báquico y telúrico Baal. Escribe Von Rad (1972: I, 50): "el yahvismo no tenía en su origen ninguna relación particular con las tierras de cultivo, [con] el fenómeno de la tierra fértil". Baal, nos dice, sí que tenía una relación de matrimonio sagrado con la tierra: fecundaba la tierra con el esperma de la lluvia y la característica fundamental de esta religiosidad consistía en la prostitución cultual, practicada en sus santuarios. El culto cananeo aportó al yahvismo sacrificios y ritos, del mismo modo que El había conferido realeza celestial a Yahvé. Con todo, la tensión debió de mantenerse durante siglos, como atestiguan las iras de los profetas dirigidas contra el politeísmo habitual de reyes y gentes del común. Aunque sin demasiado éxito: como apuntara Weber, Baal, en tanto que ligado a las actividades agrícolas, resultaba una divinidad adecuada para tiempos de paz, mientras que el culto al iracundo Yahvé y la idea de alianza adquirían vigor en tiempos de guerra.

Puede resultar sugestivo tratar de vislumbrar en esta dualidad de dioses una persistente pugna entre el espacio de Baal (tierra, cultos orgiásticos, sacrificios, repetición) y el tiempo de Yahvé (revelación, guerras, profecías, hechos singulares). En todo caso, este entreveramiento de mito e historia en la religión de Israel hizo, como dice Von Rad (ibid.: II, 142-143), que los hechos históricos que fundamentaban la comunidad de Yahvé fueran absolutos y, por tanto, repetibles en el ritual generación tras generación. La continuidad histórica tiene sentido porque está dominada por una finalidad que controla Dios: introducir a Israel en la Tierra Prometida. Olvidémonos, por tanto, de nuestra idea aséptica y positivista de historia: "la historia sólo existió para Israel en tanto que, y hasta donde, Dios había marchado con él".

Esa historia peculiar, a la que hoy nos creemos tan ajenos, enmarca en último extremo tanto el fracaso de la profecía como la muerte, una vez más, del tiempo a manos del mito y del tiempo religioso. La época postexílica supuso para Israel, como ha historiado Albertz, un intento desesperado de vuelta a los principios antijerárquicos, de recuperación de la experiencia de 
la liberación y de oposición a la monarquía. A tal fin, se colocó a Moisés en la categoría de superprofeta, "cuyo contacto cara a cara con Dios ensombrecía todas las revelaciones de carácter profético [...]. Evidentemente, Yahvé había hablado ya con y por los profetas [...], pero eso no era más que una comunicación a través de intermediarios [...]. Sólo la palabra de Moisés, sus mandamientos e instrucciones, eran la palabra auténtica y unívoca de Dios. Ésa era, por tanto, la única palabra que podría servir de norma para todo mensaje profético. Lo que pretendía esa construcción era transformar, sobre todo la ley, aunque también las instrucciones políticas de Moisés, en norma y pauta de toda proclamación profética" (Albertz 1999: 634-635). De ese modo, la profecía se remite bien al lejano pasado mosaico, bien al distante e incierto futuro, en el cual se espera que "quede totalmente abolido el control institucional sobre la profecía, puesto que Yahvé derramará su espíritu sobre todos, y el pueblo entero se convertirá en 'profeta"' (ibid.: 636-637). Es decir, habría que añadir, que la profecía se sitúa a partir de entonces fuera del ámbito de existencias concretas e históricas; en definitiva, fuera del tiempo. Estamos, en suma, ante el fracaso de la profecía y en el inicio del "proceso hacia la escatología" (ibid:: 597). Proceso que se consuma cuando la religión de Israel sobrevive a las presiones de adaptación al mundo helenístico gracias a situar definitivamente las esperanzas de liberación en el más allá: "Este desarrollo ulterior del yahvismo, que pasó de religión de liberación histórica a religión de salvación escatológica, deberá considerarse como el cambio más trascendental de la época helenística" (ibid.: 784). Y, claro está, nos encontramos así de nuevo en el terreno privilegiado de la atemporalidad, donde prospera el mito y abocan todas las religiones. Un gran estudioso de la religión judía de nuestra época, Gershom Scholem, al analizar en ella la tensión entre revelación y tradición (1998), se refiere a la defensa extremista de la segunda, que ve ejemplificada en la conclusión de Josua ben Levi, un rabino del siglo III de nuestra era: Todos los textos sagrados e "incluso lo que un discípulo precoz vaya a proponer un día a su maestro, todo le fue dicho ya a Moisés en el Sinaí". Y añade Scholem (1998: 83): frases como éstas "absolutizan el concepto de Tradición; si bien el sentido de la revelación se despliega en el tiempo histórico, ello sucede porque en un estrato fuera del tiempo ya ha sido incorporado todo lo que puede llegarse a conocer. Desembocamos en un supuesto sobre la naturaleza de la verdad que es característico del judaísmo rabínico, y quizá de toda concepción tradicionalista de la religión: la verdad está dada y fijada una vez para siempre”. ¿Pero qué religión, cabría añadir, no termina convirtiéndose en tradicionalista en ese sentido? 


\section{DIVERSIDAD EN EL MITO}

Hasta este momento he venido empleando los términos bistoria e bistórico para referirme a fenómenos y personajes que, en el mejor de los casos, distan mucho de las certezas que solemos considerar como históricas. ¿Cabe contraponerlos, sin más, a los hechos y figuras que solemos encontrar en los mitos? Es más que dudoso. Como subraya Edmund Leach a propósito de un análisis estructural de textos bíblicos, "Von Rad, como todos los investigadores biblicos ortodoxos, da por supuesto que bajo la narrativa subyace un núcleo fundamental de 'historia real', al menos desde tiempos de David en adelante. Mi escepticismo es mucho más radical: el rey David y el rey Salomón no son probablemente más históricos que el rey Agamenón y el rey Menelao" (Leach 1971: 114). Para añadir inmediatamente que la distinción entre mito e historia no es necesariamente nítida.

Sin duda, no lo es. El problema es que ninguno de esos dos términos - mito e historia - tiene tampoco significados precisos. Dejemos a un lado la polisemia, cultural y temporal, de las concepciones históricas y atendamos por un momento a la diversidad de los mitos. En este sentido, lo que me importa no es tanto la realidad factual del relato, bíblico o cualquier otro, cuanto el papel que en él juega el tiempo. Ricoeur destacó bastante tempranamente cómo los análisis lévi-straussianos parecían acomodarse bien a las clasificaciones totémicas, pero revelaban su fragilidad cuando lo que uno tiene delante es el complejo escenario del Antiguo Testamento. El estructuralismo - argumentaba Ricoeur - es un método adecuado para el estudio de un pensamiento, salvaje o totémico, que combina una gran riqueza de organización o estructura y una notable insignificancia de contenidos. En contraste, el mundo hebraico ofrece, junto a "una organización sintáctica más débil, una unión menos marcada con el rito, [y] una ligazón con las clasificaciones más tenue [...] [pero] una riqueza semántica [que] permite vías históricas indefinidas en contextos sociales más variables" (1963: 16). Es decir, el férreo primado de la forma y del orden va unido a la sincronía, del mismo modo que el acontecimiento fundador (liberación de Egipto, misión davídica, catástrofe) caracteriza al polo opuesto: "la concepción teológica exactamente inversa a la del totemismo" (ibid.: 19). De ese modo, en un extremo tendríamos el esprit bumain, tan del gusto de Lévi-Strauss, universal y atemporal, casi naturaleza ${ }^{5}$; en el otro, el ámbito de lo indeterminado y de la libertad

\footnotetext{
${ }^{5}$ Ricoeur no necesita extremar las cosas en este punto. El propio Lévi-Strauss da pie a ello cuando afirma que el propósito del método que emplea es disolver la cultura en la naturaleza: "reintegrar a la cultura en la naturaleza y, finalmente, a la vida
} 
humana, en suma. ¿Mito frente a historia, por tanto? Más bien, a mi entender, distintos tipos de mito. Como resaltara Leach, las supuestas historias bíblicas tienen más que ver con dramas - en el sentido teatral del términoque con la historia al modo académico. La propia historia inglesa del comienzo de la modernidad — venía a añadir el antropólogo británico, con ironía- ofrece contrastes (reyes y reinas vírgenes frente a otros y otras caracterizados por una intensa actividad sexual, por ejemplo) que poco o nada tienen que envidiar a la bien organizada estructura bipolar de los mitos que entusiasman a Lévi-Strauss.

Qué duda cabe de que a Lévi-Strauss le apasionaron desde bien pronto los paraísos perdidos o la nostalgia de lo absoluto ${ }^{6}$. Y un evidente rechazo hacia lo que nos hace humanos, demasiado humanos; esto es, la instalación en tiempos y lugares concretos. En su temprano Tristes trópicos, Lévi-Strauss se muestra sin rebozo entusiasmado con el modelo rousseauniano ("eterno y universal", dice) y apela lo que sería a partir de entonces su método: "ubicando fuera del tiempo y del espacio el modelo en el cual nos inspiramos [...]. Nuestra posición se reduce a decir que los hombres, siempre y en todas partes, han emprendido la misma tarea asignándose el mismo objeto y, en el curso de su devenir, sólo los medios han diferido" (1970: 394-395, cursivas mías). Y añade, casi a continuación: "desde hace milenios el hombre no ha logrado sino repetirse" (ibid:: 395). Por eso nos dirá también, años más tarde, casi al término de Mitológicas, que detrás del mito no hay sino otros mitos: "son ellos quienes hablan en él y se hacen eco unos a otros, si no hasta el infinito, cuando menos hasta el momento inasible en que, hace unos cientos de millares de años [...], la humanidad nueva profirió sus primeros mitos" (2000: 568). La necesidad, la razón última del mito, recalca el autor, "se pierde en el fondo de las edades, yace en el trasfondo del espíritu y su despliegue espontáneo se frena, se acelera, se tuerce o bifurca al sufrir constreñimientos históricos". La metáfora es sugestiva: el tiempo histórico es, simplemente, el cauce o la vía por donde el vehículo o el torrente mítico circula.

Metáfora sugestiva, pero de nuevo tan brillante como engañosa. Sencillamente, porque el tiempo o la historia son mucho más que meros escenarios

en el conjunto de sus condiciones fisicoquímicas" (1964: 358). Estas palabras corresponden a $E l$ pensamiento salvaje, que es la obra que Ricoeur toma en consideración. Con posterioridad, el antropólogo francés trataría de matizar afirmaciones como ésa, al diferenciar entre estructuralismo y reduccionismo (Cf., por ejemplo, Lévi-Strauss 1978: 9-10). En cambio, en el solemne Finale del último tomo de sus Mitológicas aparece la vieja divisa metodológica: "el estructuralismo reintegra al hombre a la naturaleza" (2000: 621).

${ }^{6}$ Los términos son, por supuesto, los de George Steiner en el librito donde se explaya con ironía sobre este autor y otros temas y autores de nuestra época (Steiner 2001). 
o paisajes de los mitos. Y además, porque aceptar algunas brillantes y fértiles premisas del estructuralismo lévi-straussiano no debería suponer el beneplácito respeto de toda la carga filosófica e ideológica que el mismo entraña. Muy concretamente: el primado absoluto de lo atemporal ${ }^{7}$. Es conocida la importancia que el antropólogo francés ha concedido al mito de Edipo y a la saga tebana como modelo de análisis de otras tradiciones míticas. Pues bien, una recapitulación del enfoque estructuralista en este ámbito - como, por ejemplo, la de Carroll (1978), a quien resumo aquí- pone de relieve varias cosas interesantes. De una parte, los aspectos válidos del método y, en especial, el hecho de que las repeticiones en cualquier narración mítica contribuyen a facilitar la circulación de sus mensajes. Así, mediante lo que en la teoría de la información se denomina redundancia, se nos pone de relieve la estructura subyacente del mito. En la saga tebana, concretamente, tales elementos se organizan en torno a una polaridad u oposición básica: hipervaloración de las relaciones de sangre frente a infravaloración de las mismas. En el método de Lévi-Strauss, tales polaridades se subsumen, a su vez, siempre y en último extremo, en una polaridad básica y universal: naturaleza frente a cultura.

No es censurable el primer paso. Cualquier narración mítica (o, tal vez, cualquier narración sin más) se organiza de ese modo. Los textos bíblicos del Viejo o del Nuevo Testamento — subraya, por ejemplo, Leach- están repletos de oposiciones binarias y de repeticiones: desde las diferentes versiones de la Creación en el Génesis a las evangélicas sobre la vida de Jesús, así como las polaridades de Caín y Abel, el ladrón bueno y el malo a uno y otro lado de la Cruz, el Alfa y la Omega o el principio y el fin... En cambio, los otros dos pasos que da Lévi-Strauss - vuelvo al trabajo de Carroll- son más que cuestionables. En primer lugar, porque el contraste que establece entre hipervaloración e infravaloración de relaciones de consanguinidad no se sostiene más que debido al desconocimiento de la saga tebana o, más probablemente, gracias a una hábil manipulación del mito para acomodarlo a las necesidades del propio análisis. Y, en segundo lugar, porque los relatos míticos helénicos revelan, en efecto, profundos antagonismos y estructuras claramente conflictivas, pero en absoluto atribuibles a elementos universales ni atemporales. Antes al contrario: el mito enmarca y refleja una decisiva transformación sociopolítica experimentada por los pueblos del área entre los siglos VIII al v antes de nuestra era. Es el proceso histórico que conlleva el tránsito de una sociedad organizada en torno al parentesco patrilineal a otra

\footnotetext{
7 Mary Douglas escribió: "Todo lo que escribe Lévi-Strauss en La pensee sauvage sobre el tiempo en ciertas culturas o a un cierto nivel de pensamiento, debería reformularse para que se aplicara sólo al método que él usa" (1968: 67).
} 
basada en la lealtad a la polis. Dicho de otro modo: el mito articula y expresa procesos históricos documentables y no vaporosas dicotomías, eternas y atemporales.

\section{MITOS RELIGIOSOS Y MITOS PROFANOS}

Quizá cabría concluir ya apuntando que hay, ciertamente, mitos que luchan contra el tiempo; son aquellos que reflejan esa ansia de eternidad (para siempre, como veíamos en la tradición a la que se refiere Scholem). No obstante, el mito que destruye el tiempo - del que parten o al que abocan todas las religiones- coexiste con el mito profano. Por mito se pueden entender muchas cosas, pero dentro de la polisemia del término hay dos rasgos distintivos que todos los mitos comparten: su carácter engañoso y su función comunicativa. Son algo así como lenguajes de segundo grado; o metalenguajes, como los denominara Lévi-Strauss. Como cualquier lenguaje, el mito siempre nos da algo de gato por liebre; sencillamente, porque toda forma de comunicación entraña algún grado de engaño o trampa. Se trata de una especie de juego que suele consistir en convencernos o persuadirnos, a través de signos clave, de que algo que tenemos ante nosotros es lo que el emisor del mensaje quiere que nos parezca, a través —entre otras cosas- de la redundancia a la que aludía antes.

De ahí, también, que los mitos se comporten como potentes sistemas de comunicación. En virtud de ellos, percibimos la realidad de una determinada manera y no de otra; pero, además, esa forma de percibir la realidad la compartimos con otras personas (personas que, por vivir en nuestra época o por pertenecer a nuestro grupo, tienen una óptica similar a la nuestra). Esos mitos profanos a los que aludía - tan bien estudiados por Roland Barthes (1999) - utilizan, como los religiosos (en definitiva, como cualquier otro lenguaje), signos; esto es, algo que sustituye a otra cosa, que la representa o que la evoca. Pero, a diferencia de los mitos religiosos, a los profanos solemos llamarlos por otros nombres y los distinguimos gracias a otros signos: nacionalismo, ecologismo, choque de civilizaciones, mercado y tantos más. Y, a diferencia de aquellos otros también, a éstos no podría aplicárseles las metáforas lévi-straussianas, ya que estos otros mitos están como impregnados de tiempo. A ellos me he referido en otros trabajos (Luque 1999, 2000). Los mitos profanos aparecen y desaparecen tan vertiginosamente a veces - en agudo contraste con lo que ocurre en el caso de los mitos que matan el tiempo- que apenas si guardamos memoria de algunos relativamente recientes. ¿Quién se acuerda ya de la huelga general política, del peligro amarillo o del imperialismo como tigre de papel del camarada Mao? Muchas veces 
apenas si los percibimos, pero están entre nosotros. Como ha advertido Cassirer (1959), así lo expresó ya un renombrado estudioso de los mitos, Max Müller, en el siglo XIx: como en tiempos de Homero, hoy tenemos mitos; pero no reparamos en ellos, sencillamente porque vivimos a su sombra.

Del mismo modo, la profecía nunca muere del todo. Resurge siempre, pero probablemente en otros ámbitos y con ropajes muy diferentes; por ejemplo, cuando nos aventuramos en otros territorios y en otros pronósticos: "la historia es sólo una labor científica en la medida en que sea posible la profecía. Cuando Schlegel dijo que el historiador era un profeta del revés, expresó una idea tan profunda como cierta" (Ortega y Gasset 1961: 22).

\section{BIBLIOGRAFÍA CITADA}

AlBERTZ, RAINER. 1999. Historia de la religión de Israel en tiempos del Antiguo Testamento, 2 vols. Madrid: Trotta.

BACON, FRANCIS. 2000. Essayes or Counsels, Civil and Moral [1597-1625]. Londres: The Folio Society.

BARTHES, ROLAND. 1999. Mitologías. Madrid: Siglo XXI.

BENDIX, REINHART. 1969. Max Weber: An Intellectual Portrait. Londres: Methuen \& Co. BENVENISTE, Émile. 1966. Problèmes de linguistique générale. París: Gallimard.

BERGER, PETER L. 1963. "Charisma and Religious Innovation: The Social Location of Israelite Prophecy". American Sociological Review 28 (6): 940-950.

Bohannan, Paul. 1967. "Concepts of Time among the Tiv of Nigeria", en John Middleton (ed.), Myth and Cosmos: Readings in Mythology and Symbolism: 315-329. Nueva York: The Natural History Press.

BURKE, KENNETH. 1970. The Rhetoric of Religion: Studies in Logology. Berkeley, California: University of California Press.

BUSTOS, EDUARDO DE. 2000. La metáfora: Ensayos transdisciplinares. Madrid: Fondo de Cultura Económica.

CARROLl, Michael P. 1978. "Lévi-Strauss on the Oedipus myth: A Reconsideration". American Anthropologist 80 (4): 805-814.

CASSIRER, ERnSt. 1959. Mito y lenguaje. Buenos Aires: Fondo de Cultura Económica.

DOUglas, Mary. 1968. "The Meaning of Myth", en E. Leach (ed.), The Structural Sudy of Myth and Totemism: 49-69. Londres: Tavistock Publications

DURKHEIM, ÉmILE. 1960. Les formes élémentaires de la vie religieuse [1912]. París: Presses Universitaires de France.

EMmET, DOROTHY. 1956. "Prophets and Their Societies". Journal of the Royal Anthropological Institute 86: 13-23.

EVANS-PRITCHARD, E. E. 1940. The Nuer. A Description of the Modes of Livehood and Political Institutions of a Nilotic People. Londres: Oxford University Press.

GASTER, THEODOR H. 1973. Mito, leyenda y costumbre en el libro del Génesis. Barcelona: Barral.

LAKOFF, G., y M. Johnson. 1980. Metaphors We Live By. Chicago: University of Chicago Press. 
LEACH, EdMund. 1971. Genesis as Myth and Other Essays. Londres: Cape Editions.

LÉvi-Strauss, Claude. 1964. El pensamiento salvaje. Ciudad de México: Fondo de Cultura Económica.

—. 1970. Tristes trópicos. Buenos Aires: EUDEBA.

-. 1978. Myth and Meaning. Londres: Routledge \& Kegan.

-. 2000. Mitológicas IV: El hombre desnudo. Ciudad de México: Siglo XXI.

LUQUE, ENRIQUE. 1974. Estudio antropológico social de un pueblo del sur. Madrid: Tecnos.

—. 1999. "De dioses, mitos, historias y sabios". Revista de Libros 31-32: 13-15.

-. 2000. "Viejos y nuevos mitos". REIS, Revista Española de Investigaciones Sociológicas 93: 9-25.

MonTAIGNE, Michel DE. 1992. Les essais [1580-1588]. Évreux: Arléa.

NEHER, ANDRÉ. 1972. La esencia del profetismo. Salamanca: Sígueme.

ORTEGA y GASSET, JOSÉ. 1961. El tema de nuestro tiempo [1923]. Madrid: Espasa-Calpe.

RAPHEL, FREDLY. 1970. "Max Weber et le judaïsme antique". Archives Européennes de Sociologie XI: 297-336.

RAPPAPORT, ROY. 2001. Ritual y religión en la formación de la bumanidad. Madrid: Cambridge University Press.

Ricoeur, Paul. 1963. "Simbolique et temporalité". Archivio di Filosofia 1-2: 5-41.

SCHOLEM, GERSHOM. 1998. Conceptos básicos del judaísmo. Madrid: Trotta.

- 2000. Las grandes corrientes de la mística judía. Madrid: Siruela.

STEINER, GEORGE. 2001. Nostalgia del Absoluto. Madrid: Siruela.

SPENGLER, OSWALD. 1998. La decadencia de Occidente [1918-1922]. Madrid: Espasa.

TAMBiah, StANLEY J. 1985. Culture, Thought and Social Action: An Anthropological Perspective. Cambridge, Mass.: Harvard University Press.

VON RAD, GERHARD. 1972. Teología del Antiguo Testamento, 2 vols. Salamanca: Sígueme. WeBER, MAX. 1952. Ancient Judaism [1917-1919]. Glencoe, Illinois: The Free Press. 